\title{
Determination of Volatile Phenol in Cabernet Sauvignon Wines, Made from Smoke-affected Grapes, by using HS-SPME GC-MS
}

\author{
C.J. de Vries ${ }^{1}$, L.M. Mokwena ${ }^{2}$, A. Buica ${ }^{1}$, M. McKay ${ }^{1 *}$ \\ (1) Department of Viticulture and Oenology, Stellenbosch University, Private Bag X1, Matieland, 7602, South Africa \\ (2) Central Analytical Facility (CAF), Stellenbosch University, Private Bag X1, Matieland, 7602, South Africa
}

Submitted for publication: August 2015

Accepted for publication: October 2015

Key words: GC-MS, smoke, wine, volatile phenols, Cabernet Sauvignon

\begin{abstract}
The increased incidence of vegetation fires near vineyards in the Western Cape, South Africa has led to growing concern over the appearance of smoke taint in the affected grapes. This study focused on the effect of smoke exposure on the volatile phenol (VP) composition of wines made from affected grapes over two vintages (2012 and 2013). Cabernet Sauvignon grapes were exposed, 10 days post-véraison, to a single, hour-long treatment with smoke derived from burning a mixture of vegetation (including fynbos) under controlled conditions in enclosures. Enclosures were sealed for $24 \mathrm{~h}$ after exposure, and then removed. Grapes were allowed to ripen and wines were then produced. Wines were analysed by headspace gas chromatography mass spectrometry (HS-SPME GC-MS) for selected volatiles. The results of the investigation show that the exposure of grapes to smoke during ripening leads to the accumulation of VPs that were detected in wines. The detected VPs were guaiacol, phenol and the cresols. Smoke exposure of grapes during ripening may have a negative impact on wine quality due to the accumulation of these compounds.
\end{abstract}

\section{INTRODUCTION}

The Western Cape region of South Africa is well known for its unique indigenous floral habitat (fynbos) (Cowling et al., 2009). The frequency of vegetation fires in the region in recent years has led to concern about smoke taint in wines made from the affected grapes (Hesseling, 2013). Investigations in Australia have confirmed that wine produced from grapes exposed to smoke from bushfires may develop objectionable, smoky, ashy and burnt characters (Sheppard et al., 2009; Hayasaka et al., 2010; Singh et al., 2011).

Plant material has a varying composition of mainly cellulose, hemicellulose and lignin (Radojevic, 2003) and, under ideal conditions, the combustion of biomass should yield only carbon dioxide and water. Bushfires, however, are seldom hot enough or supplied with enough oxygen for complete combustion of plant biomass to occur, and the accumulation of partial pyrolysis products will occur in the environment during and after the fire. Radojevic (2003) noted that emissions occur primarily during the flaming and smouldering stages, with complete combustion reactions only during flaming stages. A greater proportion of low molecular mass and highly volatile compounds are formed under flaming conditions, including phenols (Kelly, 2012).

The phenolic compounds often used as indicators of smoke exposure and potential taint are guaiacol and 4-methylguaiacol (Kennison et al., 2007; 2008; Sheppard et al., 2009). However, recent studies have shown that other volatile phenols (VPs) may also be implicated. Hayasaka et al. (2010), Kelly et al. (2012) and Parker et al. (2012) demonstrated that the presence of cresols (o-, $p$ - and $m$-cresol), phenol and syringols may account for additional taint characteristics in affected wines.

A study on the timing of grape exposure to smoke has shown that grapes are most susceptible post-véraison (Kennison et al., 2009). Subsequent findings have shown that VPs, including 4-MG, cresols, phenol, guaiacol and syringols, are metabolised into various glycoconjugated forms following uptake by grapes (Hayasaka et al., 2010; Dungey et al., 2011). Smoke-induced phenol-glycosides may accumulate and persist until maturity, when the grapes are harvested. Extraction of these phenol-glycosides from grapes during winemaking of up to $67 \%$ was reported for Cabernet Sauvignon wines (Hayasaka et al., 2010). Nonvolatile glycosylated precursors may then be hydrolysed during fermentation, ageing and wine storage (Kennison et al., 2008; Hayasaka et al., 2010).

The aim of this study was to investigate the impact of smoke from veld fires near South African vineyards on the accumulation of volatile phenols. In order to evaluate this effect, grapes in a commercial vineyard were exposed to a mixture of burning indigenous and alien plants under controlled conditions two weeks post-véraison during two

*Corresponding author: E-mail address: marianne@sun.ac.za

Acknowledgements: The authors acknowledge funding assistance from the National Research Foundation, Winetech and THRIP. We thank the staff of Stellenbosch University's experimental winery, Marisa Nell, Edmund Lakey and Andy van Wyk, for their assistance in the winemaking. We also thank and acknowledge Professor Martin Kidd, of the Centre for Statistical Consultation, Stellenbosch University, for his assistance with both the statistical analyses and data interpretation 
consecutive vintages (2012 and 2013). The smoke was produced by burning fynbos mixed with other vegetation in order to simulate smoke that might be generated by veld fires. Wines made from the smoke-affected grapes were then subjected to VP analysis by HS-SPME GC-MS, using a method adapted from Wilkinson et al. (2011) and Singh et al. (2012).

\section{MATERIALS AND METHODS}

\section{Layout of vineyards}

The experiment was carried out in the 2012 and 2013 growing seasons. The study was conducted on a Vitis vinifera L. cv. Cabernet Sauvignon clone CS 388C, grafted onto 101-14 Mgt (Vitis riparia $\mathrm{x}$ Vitis rupestris). The vineyard (1 ha) was located on the Welgevallen experimental farm at Stellenbosch (coordinates: 3356'40.3'S and 18 51'41.4'E). The vines were trained on a six-wire vertical trellis and received drip irrigation at key phenological stages, e.g. fruit-set and véraison. The vine spacing was $2.5 \times 1.4 \mathrm{~m}$, with roughly a NW to SE row direction.

Thirteen plots were selected randomly, each containing three adjacent vines. Experimental vine plots were exposed to smoke in purpose-built greenhouse-type structures, as described by Kennison et al. (2008). There was one smoke treatment and two controls. In the smoke treatments (SM, five repeats), the plots were isolated by plastic structures and subjected to a single hour-long treatment with smoke, as implemented by Sheppard et al. (2009). Similarly, in the isolated control (IC, three repeats), the vine plots were isolated by greenhouse-type structures with no smoking. In the other type of control, plots were left completely open (open control, or OC, with five repeats). The use of an isolated-type control treatment offered a statistically sound alternative in the event that open-type controls became contaminated.
The structures were built from bamboo, lashed together with cable ties and covered with greenhouse-grade plastic (Fig. 1). Selected fynbos (Leucadendron salignum, Leucadendron spissifolium, Protea repens) and pine (Pinus radiata) material was used to be representative of the flora found in the Western Cape, South Africa (Van Wilgen et al., $2010)$. This material $(25 \% \mathrm{w} / \mathrm{v}$ of each of the plant species) was burned in a drum equipped with a blower to transfer the smoke into the structures and maintain the fire (Fig. 1). Treatments were carried out as a once-off, hour-long event \pm 10 days post-véraison. The structures were then sealed for $24 \mathrm{~h}$ post-treatment to simulate the lingering smoke and increased temperatures experienced during a natural fire event, after which the structures were removed and the grapes were allowed to ripen before being harvested for vinification.

\section{Harvest and winemaking}

Grapes were picked and processed in the last week in March during the 2012 vintage and in the second week in April the following year. Véraison was roughly two weeks later in the 2013 season, and thus the time between treatment and harvest was similar. During the 2012 season there was a period of rainfall between treatment and harvest. This did not occur during the 2013 season.

Wines were made from each treatment replicate for both the 2012 and 2013 vintages from the same treatment plots, following standard winemaking methods. Grapes were crushed, de-stemmed and transferred into individual stainless steel fermenters. Sulphur dioxide $\left(\mathrm{SO}_{2}\right)$ was added to each stainless steel canister at $30 \mathrm{mg} / \mathrm{L}$ free $\mathrm{SO}_{2}$. The grapes were left to macerate for two days at $4^{\circ} \mathrm{C}$. The mash was punched down three times a day and protected from oxidation by carbon dioxide gas addition (Afrox, RSA). On the second day, the grape mash was placed in a $25^{\circ} \mathrm{C}$

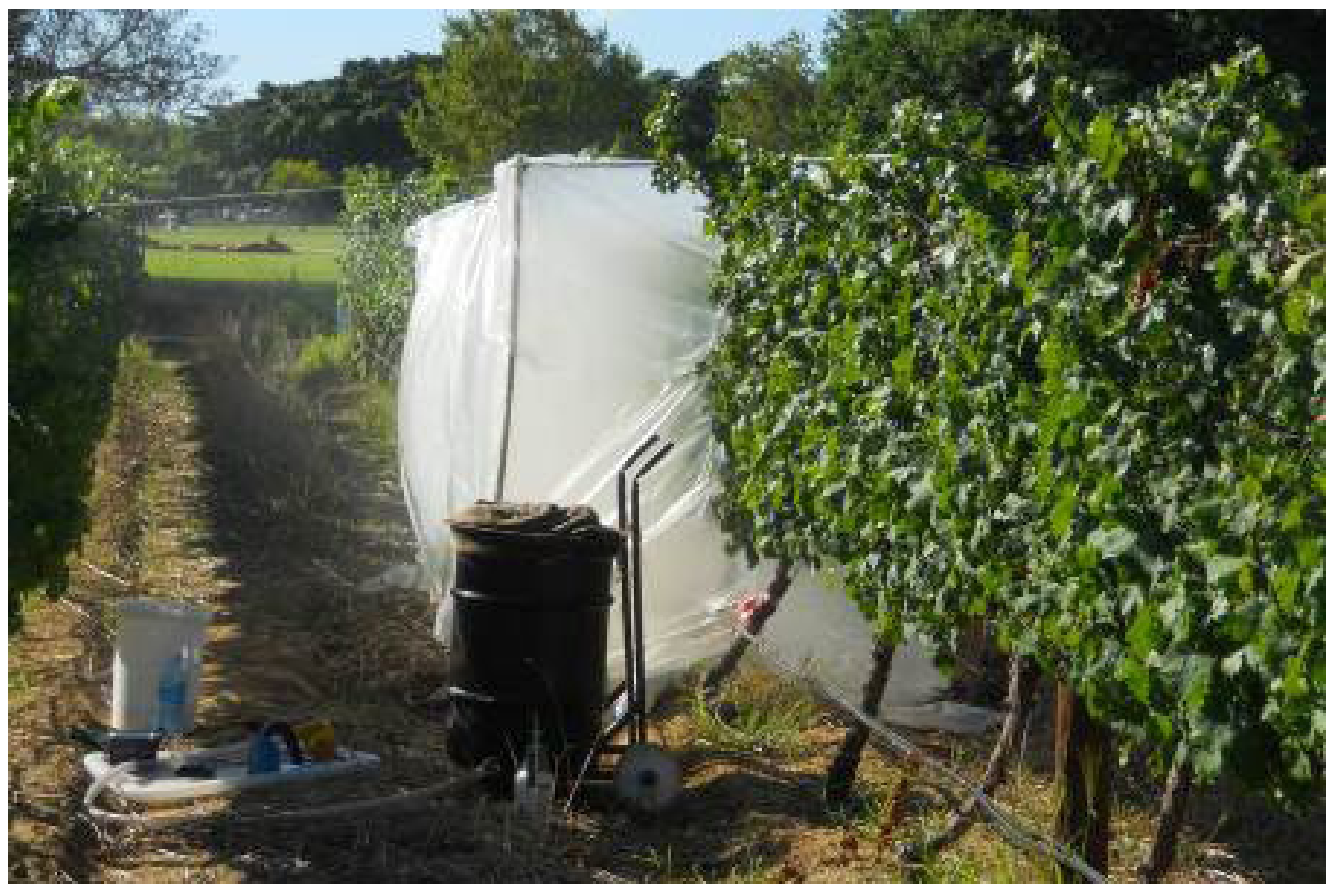

FIGURE 1

One of the SM structures during smoking. Similar structures were used for the isolated control (IC) and smoke (SM) treatments. 
fermentation room to warm up and thereafter was inoculated with $30 \mathrm{~g} / \mathrm{hL}$ of Anchor NT116 ${ }^{\circledR}$ yeast (Oenobrands ${ }^{\circledR}$, Johannesburg, RSA). The fermenting must was punched down three times and fermentation was monitored once daily by measuring mass lost using an Adam ${ }^{\circledR}$ CBC-30 scale (Adam Equipment Co. Ltd., Milton Keynes, UK). Once mass loss approached nil, samples were taken to determine the residual sugar levels (WineScan FT 120 spectrometer) (data not shown). Fermentation rates between the three treatments (smoke treated, open and isolated controls) and over both vintages did not differ significantly. All wines fermented to residual sugar levels below $2 \mathrm{~g} / \mathrm{L}$, after which the pomaces were pressed individually and then transferred into $10 \mathrm{~L}$ stainless steel canisters. Wines were not subjected to barrel maturation, as the use of toasted oak wood chips or the ageing of wines in wooden barrels may contribute to the pool of free phenols (Carrillo \& Tena, 2006). The wine was left to settle, after which it was racked off the lees into $20 \mathrm{~L}$ stainless steel canisters. $\mathrm{SO}_{2}$ was added at $50 \mathrm{mg} / \mathrm{L}$ total in addition to $200 \mathrm{~mL} / \mathrm{hL}$ of lysozyme (Lallzyme ${ }^{\circledR}$ Lyso-easy, Lallemand Inc., Montreal, Canada). The wines were then placed in a $-4^{\circ} \mathrm{C}$ room for two weeks for cold stabilisation, after which they were racked and stored at $15^{\circ} \mathrm{C}$. The levels of free $\mathrm{SO}_{2}$ were adjusted to $40 \mathrm{mg} / \mathrm{L}$, and the wine was filtered through a coarse mat filter with diatomaceous earth and bottled in $750 \mathrm{~mL}$ glass bottles (Consol glass, RSA), sealed with 'SAVin' (MCG Industries (Pty) Ltd., Paarden Eiland, RSA) aluminium screw caps. In both vintages, the experimental wines were stored at $-4^{\circ} \mathrm{C}$ for two weeks and then stored for four months at $15^{\circ} \mathrm{C}$ before being bottled. The bottled wines were analysed in July 2013.

\section{Stock preparation for volatile phenol analysis}

A custom-made stock solution used for calibration containing the following: 4-ethylguaiacol (4-EG), 4-ethylphenol (4EP), phenol, $o$-cresol, $p$-cresol, $m$-cresol, 2,3-xylenol (2,3Xyl), 2,6-xylenol (2,6-Xyl) and 3,4-xylenol (3,4-Xyl), at concentrations of $100 \mathrm{mg} / \mathrm{L}$ in methanol, which were purchased from Anatech Instruments (Pty) Ltd., Gauteng, RSA. Guaiacol, eugenol and 4-vinylphenol (4-VP) were purchased from Sigma-Aldrich (Sigma, St. Luis, MO, USA), and 4-methylguaiacol (4-MG) were purchased from Fluka (Buchs, Switzerland) and prepared in methanol at concentrations of $100 \mathrm{mg} / \mathrm{L}$. The deuterated internal standard chosen was anisole-d8 (methoxybenzene-d8; Sigma, St. Luis, MO, USA). A 30\% w/v NaCl (Merck, Germany) solution was made up in ultra-pure distilled water (Millipore, Bedford, MA, USA). Synthetic wine made for calibrations had the following composition: $1 \% \mathrm{v} / \mathrm{v}$ ethanol $(96.4 \% \mathrm{v} / \mathrm{v}$ ethyl alcohol, Illovo Sugar Limited, RSA), $6 \mathrm{~g} / \mathrm{L}$ tartaric acid (Sigma-Aldrich, St. Luis, MO, USA), at a pH of 3.5.

\section{Calibration}

An eight-point calibration was done by spiking $10 \mathrm{~mL}$ aliquots of synthetic wine with the compounds of interest at their relevant concentrations from stock solutions. The range of calibration was from 0.05 to $25 \mu \mathrm{g} / \mathrm{L}$, with two repeats for each level. The calibration curve was plotted by the ratio obtained by dividing the areas of the respective volatile with the area of the internal standard. The concentrations of the
VPs in the samples were read against the calibration curves.

The parameters of the calibration are shown in Table 1. The limit of detection (LOD) and limit of quantitation (LOQ) for the analytes were calculated using the instrumental signal-to-noise ratio of 3:1 for LOD and 10:1 for LOQ.

\section{Sample preparation for volatile phenol analysis (HS-} SPME GC-MS)

A $10 \mathrm{~mL}$ aliquot of samples (standard or wine) was transferred into $20 \mathrm{~mL}$ amber SPME glass vials (Gerstel, Mülheim an der Ruhr, Germany). A total of $100 \mu \mathrm{L}$ internal standard at a final concentration of $10 \mu \mathrm{g} / \mathrm{L}$ (in acetonitrile) and $2 \mathrm{~mL}$ of $30 \%(\mathrm{w} / \mathrm{v}) \mathrm{NaCl}$ solution were added to each vial and the vials were sealed with PTFE-lined magnetic crimp caps (Gerstel, Mülheim an der Ruhr, Germany). Sample vials were vortexed for 30 seconds (Vortex-Genie ${ }^{\circledR}$ 2; Scientific Industries Inc., NY, USA) before being placed on the autosampler (CTC Analytics PAL) for analysis. Samples were analysed in duplicate.

Vials were incubated in the autosampler at $50^{\circ} \mathrm{C}$ for five minutes, after which a 50/30 $\mu \mathrm{m}$ divinylbenzene/carboxen/ polydimethylsiloxane (DVB/CAR/PDMS) SPME fibre (Supelco, Bellafonte, PA, USA) was exposed to the headspace of the vial for 30 minutes at the same temperature. After equilibration, the fibre was then injected onto the injector at $250^{\circ} \mathrm{C}$, and 10 minutes were allowed for desorption of the compounds.

\section{Chromatographic conditions}

The analysis was performed using an Agilent GC, model 6890 N (Agilent, Palo Alto, CA, USA), coupled with an Agilent mass spectrometer detector (MS), model 5975B Inert XL EI/CI (Agilent, Palo Alto, CA, USA) equipped with a CTC Analytics PAL autosampler. The chromatographic separation of the volatile phenols was performed on a polar J\&W DB-FFAP (60 m, $0.25 \mathrm{~mm}$ i.d., $0.5 \mu \mathrm{m}$ film thickness) capillary column. The oven temperature program was as follows: $40^{\circ} \mathrm{C}$ held for $1 \mathrm{~min}$, then ramped up to $150^{\circ} \mathrm{C}$ at $25^{\circ} \mathrm{C} / \mathrm{min}$ and held for $3 \mathrm{~min}$, and again ramped up to $200^{\circ} \mathrm{C}$ at $5^{\circ} \mathrm{C} / \mathrm{min}$ and held for $5 \mathrm{~min}$, and finally up to $250^{\circ} \mathrm{C}$ at $5^{\circ} \mathrm{C} / \mathrm{min}$ and held there for $2 \mathrm{~min}$. The total run time for the method was $30.54 \mathrm{~min}$. Helium at a constant flow rate of $1.0 \mathrm{~mL} / \mathrm{min}$ was used as a carrier gas. The injector operated in a splitless mode that was maintained at $250^{\circ} \mathrm{C}$ throughout the analysis. Both the purge flow and gas saver flow were activated at $50 \mathrm{~mL} / \mathrm{min}$ for two and five minutes respectively. The MS-detector was operated in single ion monitoring (SIM) mode. The ion source and quadrupole temperatures were maintained at $230^{\circ} \mathrm{C}$ and $150^{\circ} \mathrm{C}$, respectively, with the transfer line set at $250^{\circ} \mathrm{C}$.

Compounds were identified using GC-MS retention times and cross-referencing their mass spectra with the NIST05 spectral library. Quantifier ions are shown in Table 2.

\section{Data analysis}

The data was analysed using Statistica 12 software. Twoway ANOVA was conducted to determine treatment effect, vintage effect and treatment/vintage interaction. Fisher's least significant difference (LSD) corrections were used for post hoc analyses. Significant differences were assessed on a $5 \%$ significance level $(p<0.05)$. 


\section{RESULTS AND DISCUSSION}

All compounds, with the exception of 3,4-xylenol, were detected in the experimental wines. The results for the individual vintages are presented in Table 3. Concentrations of 4-methyl guaiacol (4-MG), 4-vinyl guaiacol (4-VG), 4-ethyl guaiacol (4-EG) and 4-ethyl phenol (4-EP) were detected below the LOQ levels of $2.72 \mu \mathrm{g} / \mathrm{L}, 3.67 \mu \mathrm{g} / \mathrm{L}$, $2.31 \mu \mathrm{g} / \mathrm{L}$ and $2.94 \mu \mathrm{g} / \mathrm{L}$, respectively. These compounds therefore were not analysed statistically or included in the table. 4-Methylguaiacol (4-MG) and eugenol were only detected in wines made during the 2012 vintage from smoketreated grapes. While 4-MG was found in only two wines, eugenol was found in all wines made from smoke-treated grapes for the 2012 vintage.

In 2012 there were statistically significant differences between the smoke and control treatments for the levels of guaiacol, phenol, $o-, p$ - and $m$-cresol ( $p=0.002$ for guaiacol and $p \leq 0.001$ for phenol, $o-, p$ - and $m$-cresol) (Table 3 ).

Fisher's LSD test confirmed that, for all compounds ( $p \geq 0.05$ ), the IC and OC (control) treatments were not significantly different from one another. In contrast, smokeaffected wines differed significantly from the open $(p \leq 0.001$; all compounds) and isolated control ( $p=0.004$ for guaiacol and $p \leq 0.001$ for phenol, $o-, p$ - and $m$-cresol) samples in 2013. Vintage effect was not significant for guaiacol, phenol or the $o-, p$ - and $m$-cresol compounds ( $p>0.05$ ).

Most of the VPs were detected at concentrations below individual odour detection threshold levels (Table 4). Only guaiacol levels for the 2012 vintage achieved a concentration marginally higher than the $7.5 \mu \mathrm{g} / \mathrm{L}$ threshold reported for

TABLE 1

Retention times (RT), correlation coefficient $\left(\mathrm{R}^{2}\right)$, limit of detection (LOD) and limit of quantitation (LOQ) for the GC-MS method.

\begin{tabular}{lllll}
\hline Compound & $\mathbf{R T}$ & $\mathbf{R}^{\mathbf{2}}$ & $\mathbf{L O D}(\boldsymbol{\mu g} / \mathbf{L})$ & $\mathbf{L O Q}(\boldsymbol{\mu g} / \mathbf{L})$ \\
\hline IS (anisole-d8) & 7.296 & - & - & - \\
Guaiacol & 14.375 & 1 & 0.410 & 1.366 \\
2,6-Xylenol & 15.006 & 0.999 & 0.975 & 3.250 \\
4-Methylguaiacol & 15.841 & 0.999 & 0.816 & 2.720 \\
o-Cresol & 16.382 & 1 & 0.512 & 1.705 \\
Phenol & 16.487 & 0.998 & 1.275 & 4.249 \\
4-Ethylguaiacol & 17.016 & 0.999 & 0.692 & 2.308 \\
$\boldsymbol{p}$-Cresol & 17.844 & 0.999 & 0.693 & 2.309 \\
m-Cresol & 18.000 & 0.999 & 0.686 & 2.285 \\
2,3-Xylenol & 19.270 & 1 & 0.320 & 1.065 \\
4-Ethylphenol & 19.788 & 0.999 & 0.883 & 2.942 \\
Eugenol & 19.929 & 0.998 & 1.213 & 4.044 \\
4-Vinylguaiacol & 20.563 & 0.998 & 1.101 & 3.670 \\
3,4-Xylenol & 21.022 & 0.998 & 1.103 & 3.676 \\
\hline
\end{tabular}

TABLE 2

Quantifying ion (QI) and monitored ions of compounds quantified.

\begin{tabular}{lcccc}
\hline Compound & QI & & Monitored ions $\boldsymbol{m} / \mathbf{z}$ & 98 \\
\hline IS (anisole-d8) & 116 & 116 & 84 & 124 \\
Guaiacol & 109 & 81 & 109 & 122 \\
2,6-Xylenol & 122 & 107 & 138 & - \\
4-Methylguaiacol & 138 & 123 & 108 & 122 \\
o-Cresol & 107 & 107 & 66 & - \\
Phenol & 94 & 94 & 152 & - \\
4-Ethylguaiacol & 137 & 137 & 108 & 122 \\
p-Cresol & 107 & 107 & 108 & - \\
m-Cresol & 107 & 107 & 122 & - \\
2,3-Xylenol & 107 & 107 & 122 & - \\
4-Ethylphenol & 107 & 107 & 149 & 164 \\
Eugenol & 122 & 122 & 135 & - \\
4-Vinylguaiacol & 150 & 107 & 122 & \\
3,4-Xylenol & 107 & 107 & & \\
\hline
\end{tabular}


young red wines by Ferreira et al. (2000).

No significant differences were found in the levels of 2,6-xylenol between wines from different treatments $(p \geq 0.05)$. The same non-significant treatment trend was seen for the 2012 and 2013 vintages. A vintage effect was found to be significant for 2,6-xylenol, with higher levels for the 2013 vintage $(p=0.006)$.

The rainfall that occurred between treatment and harvest in the 2012 season may have rinsed away some surface ash in the smoke-treated plots, but this did not seem to have an effect on the levels of most of the VPs, as guaiacol, phenol, $o-, p$ - and $m$-cresol all showed similar trends over both vintages.

4-Ethylguaiacol was only detected in one of the smoke- affected wines $(0.70 \mu \mathrm{g} / \mathrm{L}$ for the 2012 vintage $)$. During the smoke treatments of individual field repeats, the density of the smoke was not measured, as in the study by Kelly et al. (2012), in which a laser nephelometer was used to regulate smoke density during treatments. In the current study, smoke density was evaluated subjectively. The smoke generator may not have been smoking adequately when the first treatment repeat was done, thus generating a lower amount of smoke than in subsequent trials.

Experimental wines were bottled within four months of production in both the 2012 and 2013 vintages. The wines were then stored at a constant temperature of $15^{\circ} \mathrm{C}$ before volatile fraction analysis was carried out on both sets of wines in 2013. Wines from the earlier vintage therefore spent

TABLE 3

Concentration of volatile phenols $(\mu \mathrm{g} / \mathrm{L}) *$ found in Cabernet Sauvignon experimental wines for the 2012 and 2013 vintages.

\begin{tabular}{|c|c|c|c|c|c|c|c|c|c|c|}
\hline Treatment & Vintage & Guaiacol & $\begin{array}{l}\text { 4-Methyl } \\
\text { Guaiacol }\end{array}$ & Phenol & $\begin{array}{l}o- \\
\text { Cresol }\end{array}$ & $\begin{array}{l}p \text { - } \\
\text { Cresol }\end{array}$ & $\begin{array}{l}m- \\
\text { Cresol }\end{array}$ & $\begin{array}{l}\text { 2,3- } \\
\text { Xylenol }\end{array}$ & $\begin{array}{l}2,6- \\
\text { Xylenol }\end{array}$ & Eugenol \\
\hline Smoke & 2012 & $\begin{array}{l}8.62 \\
(7.31) \mathrm{a}\end{array}$ & $\begin{array}{l}1.36^{\#} \\
(0.72)\end{array}$ & $\begin{array}{l}27.99 \\
(14.13) \mathrm{a}\end{array}$ & $\begin{array}{l}6.01 \\
(2.64) \mathrm{a}\end{array}$ & $\begin{array}{l}4.21 \\
(1.35) \mathrm{a}\end{array}$ & $\begin{array}{l}3.32 \\
(1.21) \mathrm{a}\end{array}$ & $\begin{array}{l}0.44 \\
(0.10)\end{array}$ & $\begin{array}{l}859.72 \\
(52.19) \mathrm{a}\end{array}$ & $\begin{array}{l}1.52 \\
(0.14)\end{array}$ \\
\hline Open control & 2012 & $\begin{array}{l}1.90 \\
(0.45) \mathrm{b}\end{array}$ & nd & $\begin{array}{l}7.63 \\
(0.73) b\end{array}$ & $\begin{array}{l}2.70 \\
(0.39) \mathrm{b}\end{array}$ & $\begin{array}{l}1.20 \\
(0.10) b\end{array}$ & $\begin{array}{l}1.64 \\
(0.20) \mathrm{b}\end{array}$ & nd & $\begin{array}{l}832.69 \\
(45.61) \mathrm{a}\end{array}$ & $\begin{array}{l}1.50 \\
(0.17)\end{array}$ \\
\hline $\begin{array}{l}\text { Isolated } \\
\text { control }\end{array}$ & 2012 & $\begin{array}{l}1.99 \\
(0.22) b\end{array}$ & nd & $\begin{array}{l}7.36 \\
(0.55) b\end{array}$ & $\begin{array}{l}3.09 \\
(0.46) \mathrm{b}\end{array}$ & $\begin{array}{l}1.41 \\
(0.22) b\end{array}$ & $\begin{array}{l}1.70 \\
(0.32) b\end{array}$ & nd & $\begin{array}{l}876.18 \\
(77.06) \mathrm{a}\end{array}$ & $\begin{array}{l}1.38 \\
(0.21)\end{array}$ \\
\hline Smoke & 2013 & $\begin{array}{l}6.94 \\
(2.40) \mathrm{a}\end{array}$ & nd & $\begin{array}{l}23.69 \\
(4.64) \mathrm{a}\end{array}$ & $\begin{array}{l}5.94 \\
(1.10) \mathrm{a}\end{array}$ & $\begin{array}{l}3.55 \\
(0.83) a\end{array}$ & $\begin{array}{l}2.98 \\
(0.39) \mathrm{a}\end{array}$ & $\begin{array}{l}0.39 \\
(0.04)\end{array}$ & $\begin{array}{l}960.76 \\
(79.16) \mathrm{a}\end{array}$ & nd \\
\hline Open control & 2013 & $\begin{array}{l}1.71 \\
(0.21) b\end{array}$ & nd & $\begin{array}{l}12.72 \\
(1.95) b\end{array}$ & $\begin{array}{l}3.33 \\
(0.68) b\end{array}$ & $\begin{array}{l}1.74 \\
(0.10) b\end{array}$ & $\begin{array}{l}2.06 \\
(0.47) \mathrm{ab}\end{array}$ & nd & $\begin{array}{l}932.05 \\
(136.75) \\
a\end{array}$ & nd \\
\hline $\begin{array}{l}\text { Isolated } \\
\text { control }\end{array}$ & 2013 & $\begin{array}{l}2.07 \\
(0.63) \mathrm{b}\end{array}$ & nd & $\begin{array}{l}12.09 \\
(1.69) \mathrm{b}\end{array}$ & $\begin{array}{l}3.48 \\
(0.42) b\end{array}$ & $\begin{array}{l}1.92 \\
(0.03) \mathrm{b}\end{array}$ & $\begin{array}{l}2.21 \\
(0.13) \mathrm{b}\end{array}$ & nd & $\begin{array}{l}991.01 \\
(80.75) \mathrm{a}\end{array}$ & nd \\
\hline
\end{tabular}

* Values are means (SD) for quintuplicate analysis (open control and smoke treatments, $n=5$ ) and for triplicate analysis (open control, $\mathrm{n}=3$ ); letters denote differences in treatment means per vintage year at a $5 \%$ significance level

\# Mean of two samples

nd $=$ not detected

TABLE 4

Aroma descriptors and odour detection threshold (OT) for volatile phenols in red wine, ${ }^{(*)}$ in synthetic wine or ${ }^{(* *)}$ in water.

\begin{tabular}{|c|c|c|c|}
\hline Compound & Aroma descriptors & OT $(\mu \mathrm{g} / \mathrm{L})$ & Reference \\
\hline Guaiacol & Smoke, sweet, medicinal & $7.5^{(1)}-23^{(2)}$ & $\begin{array}{l}{ }^{(1)} \text { Ferreira et al. (2000) } \\
\text { (2) Parker et al. (2012) }\end{array}$ \\
\hline 4-Methylguaiacol & Ashy, toasted & 65 & Kennison et al. 2009 \\
\hline 4-Vinylguaiacol & Clove, curry & $40 *$ & Parker et al. 2012 \\
\hline 4-Ethylguaiacol & Smoke, spicy, toasted & 110 & Kennison et al. 2009 \\
\hline 4-Ethylphenol & Barnyard, horsey, phenolic & 605 & Kennison et al. 2009 \\
\hline Phenol & Sickeningly sweet ${ }^{(3)}$, irritating & $7100 *$ & $\begin{array}{l}\text { Parker et al. } 2012 \\
{ }^{(3)} \text { Panzeri, (2013) }\end{array}$ \\
\hline$o$-Cresol & Band-aid, medicinal, smoky & 62 & Parker et al. 2012 \\
\hline p-Cresol & Band-aid, phenol like & 64 & Parker et al. 2012 \\
\hline m-Cresol & Dry, tarry, medicinal-leathery & 20 & Parker et al. 2012 \\
\hline 2,3-Xylenol & Phenolic & $500 * *$ & Verschueren 1983. \\
\hline 2,6-Xylenol & Medicinal, phenolic & $570 *$ & Escudero et al. 2007 \\
\hline Eugenol & Clove & $6^{*}$ & Escudero et al. 2007 \\
\hline
\end{tabular}


more than a year in storage. Other workers have suggested that tests for smoke compounds should include the testing of glycoconjugated VP precursors in order to better predict taint potential (Dungey et al., 2011; Wilkinson et al., 2011; Parker et al., 2012). In this study, differences in guaiacol concentration were not significantly different over the two vintages. A small difference ( $1.68 \mu \mathrm{g} / \mathrm{L}$ higher) was found for smoked wines from the 2012 vintage. While this is only a hypothesis, it can be suggested that one year was not sufficient time for the hydrolysis of phenol glycosides under these storage conditions. Singh et al. (2011) reported increases in free guaiacol and 4-MG in bottled wine that had been under storage for two to three years.

No vintage effect was observed, other than on levels of 2,6-xylenol. This may have been due to the fact that the smoke generation was not completely consistent or quantifiable. The smoke treatment period in this study was also very brief (one hour), and it may be that longer exposure would better imitate a 'real' bushfire situation in which vineyards may be exposed to odorous conditions for many hours or even days. Repeating the trial with a longer exposure time might add useful data. It would be important and useful, too, to the South African wine industry if the testing of volatile phenols could include bound phenolic-glycosides in grapes pre-harvest and in juice samples. Producers would be able to better gauge the potential for taint and thereby better manage or prevent the production of tainted wines. This principle would also apply to grapes exposed to other sources of volatile phenols. These results are limited in that only the volatile phenols were analysed. Thus, the full contribution of free forms and bound, non-volatile phenolic glycosides was not estimated and will be the subject of a future study, as will an analysis of commercial South African wines that have been affected by recent bushfires.

Although the VP levels detected were below the odour threshold in this study, sensory research conducted previously has shown that these compounds have a synergistic effect on each other (Panzeri, 2013). This suggests that smoke exposure of grapes during ripening may have a negative impact on wine quality, even if the individual compounds are present at low or threshold levels. Sensory evaluation of the affected wines also will form the subject of a future paper.

\section{CONCLUSIONS}

In this study, wines made from grapes treated with burning fynbos and pine needles under controlled conditions were evaluated for volatile phenols (VPs) using a specially developed HS-SPME GC-MS method. It was demonstrated that a single, hour-long smoke treatment 10 days postvéraison was sufficient to increase the levels of phenol, guaiacol, $o-, p$ - and $m$-cresol in Cabernet Sauvignon wines produced from smoke-affected grapes. This was consistent over both treatment vintages. For both vintages the wines made from grapes exposed to smoke had significantly higher levels of the VPs compared to the controls, while there were no significant differences between the two types of controls used. Additionally, there were no significant differences between the vintages within the same type of treatment. Levels of free VPs detected were below published odour thresholds.
The VP analysis currently offered by commercial South African wine laboratories is limited to testing for guaiacol and 4-ethylguaiacol in free volatile fractions. Although the method employed in this study was able to analyse a much wider range of VPs, authors have suggested that testing for smoke compounds should include an analysis for precursors in order to better predict taint potential. With another extremely hot, dry season predicted for 2016, the possibility of fynbos veld fires close to vineyards persists, and testing should be offered to producers that includes both volatile phenols and bound phenolic-glycosides in smokeaffected grapes pre-harvest and in juice samples. With this methodology in place, producers would be able to gauge the potential for taint and thereby better manage or prevent the production of tainted wines. Method development for the analysis of glycoconjugated VP precursors, the investigation of smoke-derived volatiles in other cultivars, and the remediation of taint through winemaking technologies will be the subjects of future studies.

\section{LITERATURE CITED}

Carrillo, J.D. \& Tena, M.T., 2006. Determination of volatile oak compounds in aged wines by multiple headspace solid-phase microextraction and gas chromatography-mass spectrometry (MHS-SPME-GC-MS). Anal. Bioanal. Chem. 38, 937-943.

Cowling, R.M., Proches, S. \& Partridge, T.C., 2009. Explaining the uniqueness of the Cape flora: Incorporating geomorphic evolution as a factor for explaining its diversification. Mol. Phylogenet. Evol. 51, 64-74.

Dungey, K.A., Hayasaka, Y. \& Wilkinson, K.L., 2011. Quantitative analysis of glycoconjugate precursors of guaiacol in smoke-affected grapes using liquid chromatography-tandem mass spectrometry based stable isotope dilution analysis. Food Chem. 126, 801-806.

Escudero, A., Campo, E., Farina, L., Cacho, J. \& Ferreira, V., 2007. Analytical characterization of the aroma of five premium red wines. Insights into the role of odor families and the concept of fruitiness of wines. J. Agric. Food Chem. 55, 4501-4510.

Ferreira, V., López, R. \& Cacho, J.F., 2000. Quantitative determination of the odorants of young red wines from different grape varieties. J. Sci. Food Agric. 80,1659-1667.

Hayasaka, Y., Baldock, G.A., Parker, M., Pardon, K.H., Black, C.A., Herderich, M.J. \& Jeffery, D.W., 2010. Glycosylation of smoke-derived volatile phenols in grapes as a consequence of grapevine exposure to bushfire smoke. J. Agric. Food Chem. 58, 10989-10998.

Hesseling, E., 2013. Where there's smoke. WineLand Magazine, March 2013. Available at: http://www.wineland.co.za/articles/where-there-ssmoke.

Kelly, D. 2012. Smoke taint in wine unchanged by differences in vegetation. Aust. N.Z. Grapegrow. Winemak. 582, 59-60.

Kelly, D., Zerihun, A., Singh, D.P., Von Eckstaedt, C.V., Gibberd, M., Grice, K. \& Downey, D., 2012. Exposure of grapes to smoke of vegetation with varying lignin composition and accretion of lignin derived putative smoke taint compounds in wine. Food Chem. 135, 787-798.

Kennison, K.R., Gibberd, M.R., Pollnitz, A.P. \& Wilkinson, K.L., 2008. Smoke derived taint in wine: The release of smoke-derived volatile phenols during fermentation of merlot juice following grapevine exposure to smoke. J. Agric. Food Chem. 56, 7379-7383.

Kennison, K.R., Wilkinson, K.L., Pollnitz, A.P., Williams H.G. \& Gibberd, M.R., 2009. Effect of timing and duration of grapevine exposure to smoke on the composition and sensory properties of wine. Aust. J. Grape Wine Res. 15, 228-237 
Kennison, K.R., Wilkinson, K.L., Williams, H.G., Smith, J.H. \& Gibberd, M.R., 2007. Smoke-derived taint in wine: |Effect of postharvest smoke exposure of grapes on the chemical composition and sensory characteristics of wine. J. Agric. Food Chem. 55, 10897-10901.

Panzeri, V., 2013. Influence of vineyard posts type on the chemical and sensorial composition of Sauvignon blanc and Merlot noir wines. Thesis, Stellenbosch University, Private Bag X1, 7602 Matieland (Stellenbosch), South Africa.

Parker, M., Osidacz, P., Baldock, G.A., Hayasaka, Y., Black, C.A., Pardon, K.H., Jeffery, D.W., Geue, J.P., Herderich, M.J. \& Francis, I.L., 2012 Contribution of several volatile phenols and their glycoconjugates to smokerelated sensory properties of red wine. J. Agric. Food Chem. 60, 2629-2637.

Radojevic, M., 2003. Chemistry of forest fires and regional haze with emphasis on Southeast Asia. Pure Appl. Geophys. 160, 157-187.

Sheppard, S.I., Dhesi, M.K. \& Eggers N.J., 2009. Effect of pre- and postveraison smoke exposure on guaiacol and 4-methylguaiacol concentration in mature grapes. Am. J. Enol. Vitic. 60, 98-103.
Singh, D.P., Chong, H.H., Pitt, K.M., Cleary, M., Dokoozlian, N.K. \& Downey M.O., 2011. Guaiacol and 4-methylguaiacol accumulate in wines made from smoke-affected fruit because of hydrolysis of their conjugates. Aust. J. Grape Wine Res. 17, 13-21.

Singh, D.P. Zerihun, A., Kelly, D., Cain, M., Nankervis, P. \& Downey, M., 2012. A GC-MS based analytical method for detection of smoke taint associated phenols in smoke affected wines. Curr. Bioact. Compd. 8(3), 190-199.

Van Wilgen, B.W., Forsyth, G.G., De Klerk, H., Das, S., Khuluse, S. \& Schmitz, P., 2010. Fire management in Mediterranean-climate shrub lands A case study from the Cape fynbos, South Africa. J. Appl. Ecol. 47, 631-638.

Verschueren, K. 1983 ( $2^{\text {nd }}$ ed). Handbook of environmental data of organic chemicals. New York, NY: Van Nostrand Reinhold Co.

Wilkinson, K.L., Ristic, R., Pinchbeck, K.A., Fudge, A.L., Singh, D.P., Pitt., K.M., Downey, M.O., Baldock, G.A., Hayasaka, Y., Parker, M. \& Herderich, M.J., 2011. Comparison of methods for the analysis of smoke related phenols and their conjugates in grapes and wine. Aust. J. Grape Wine Res. 17, 22-28. 